\title{
Ty21a Typhoid Vaccine
}

National Cancer Institute

\section{Source}

National Cancer Institute. Ty21a Typhoid Vaccine. NCI Thesaurus. Code C97126.

A live attenuated bacteria oral vaccine used to prevent typhoid, which is caused by Salmonella typhi. 